\title{
Prevention Strategies of Contrast Medium Induced Nephropathy (CIN): A Review of the Current Literature
}

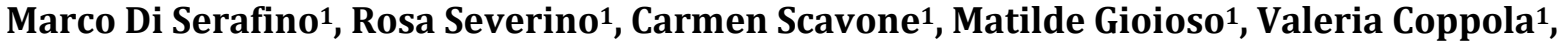 Raffaela Brigida1 $^{1}$, Francesco Lisanti², Rosario Rocca ${ }^{1}$, Enrico Scarano ${ }^{1}$}

${ }^{1}$ Radiology Department, San Carlo Hospital, Potenza, Italy

${ }^{2}$ Emergency Department, San Carlo Hospital, Potenza, Italy

Email: marcodiserafino@hotmail.it

How to cite this paper: Di Serafino, M., Severino, R., Scavone, C., Gioioso, M., Coppola, V., Brigida, R., Lisanti, F., Rocca, R. and Scarano, E. (2016) Prevention Strategies of Contrast Medium Induced Nephropathy (CIN): A Review of the Current Literature. Open Journal of Nephrology, 6, 98-110. http://dx.doi.org/10.4236/ojneph.2016.63013

Received: July 30, 2016

Accepted: September 27, 2016

Published: September 30, 2016

Copyright $\odot 2016$ by authors and Scientific Research Publishing Inc. This work is licensed under the Creative Commons Attribution International License (CC BY 4.0).

http://creativecommons.org/licenses/by/4.0/

\begin{abstract}
Contrast medium induced nephropathy is the third most common cause of renal failure for inpatients and represents the $10 \%$ of all acute kidney injury occurring during hospital-stay. It is associated with prolonged hospitalization, cost increase and, above all, an unfavourable short- and long-term prognosis. Here, the authors discuss about the contrast medium induced nephropathy prevention strategies, from the identification of patients at risk and drugs potentially nephrotoxic, to the hydration with possible administration of drugs that appeared to be, in some contexts, nephron-protective, and finally we analyze the radiological procedure aimed at the correct choice of type and administration modality of the contrast medium according to current literature.
\end{abstract}

\section{Keywords}

Contrast Medium, Acute Kidney Injury, Hydration

\section{Introduction}

Contrast medium Induced Nephropathy (CIN) is the third most common cause of renal failure for inpatients and represents the $10 \%$ of all Acute Kidney Injury (AKI) occurring during hospital-stay. It is associated with prolonged hospitalization, cost increase and, above all, an unfavourable short- and long-term prognosis with acceleration of chronic renal disease [1]-[3]. The imaging techniques most frequently associated with CIN are coronary angiography and Computed Tomography (CT) acquired after Contrast Medium (CM) administration. Both these exams are extensively required in 
the current clinical practice [4].

Prospective studies of hospitalised patients with AKI demonstrate that CM administration is directly responsible or concurrent to renal failure development in the " $11 \%$ $14.5 \%$ of cases" [5]-[7]. Therefore, the AKI development is considered a significant complication of $\mathrm{CM}$ and it has been related to an increase both in morbidity and mortality despite the fact that the recent use of low osmolarity or iso-osmolar CM has significantly reduced the risk [8] [9].

\section{Definition}

To date, CIN is defined as an acute alteration of the renal function resulting in an increase of serous creatinine level greater than $25 \%$ compared to the basal values (preexam) or an absolute increase of creatinine level equal or superior to $0.5 \mathrm{mg} / \mathrm{dl}$ occurred within 48 - 72 hours following the patient exposition to CM, in absence of other possible causes of AKI [10].

CIN represents the development of renal damage that may verify after the CM administration, in absence of other identifiable causes, and it is widely recognised as one of the main causes of acquired renal insufficiency [10].

The exact pathophysiology of CIN development is still unknown but it is assumed that hypoxia, oxidative stress and free radicals produced in the renal medulla cause acute vasoconstriction, which determines renal hypo perfusion. In addition, it seems that there is direct CM toxic effect on the tubular epithelium (Figure 1) [11] [12].

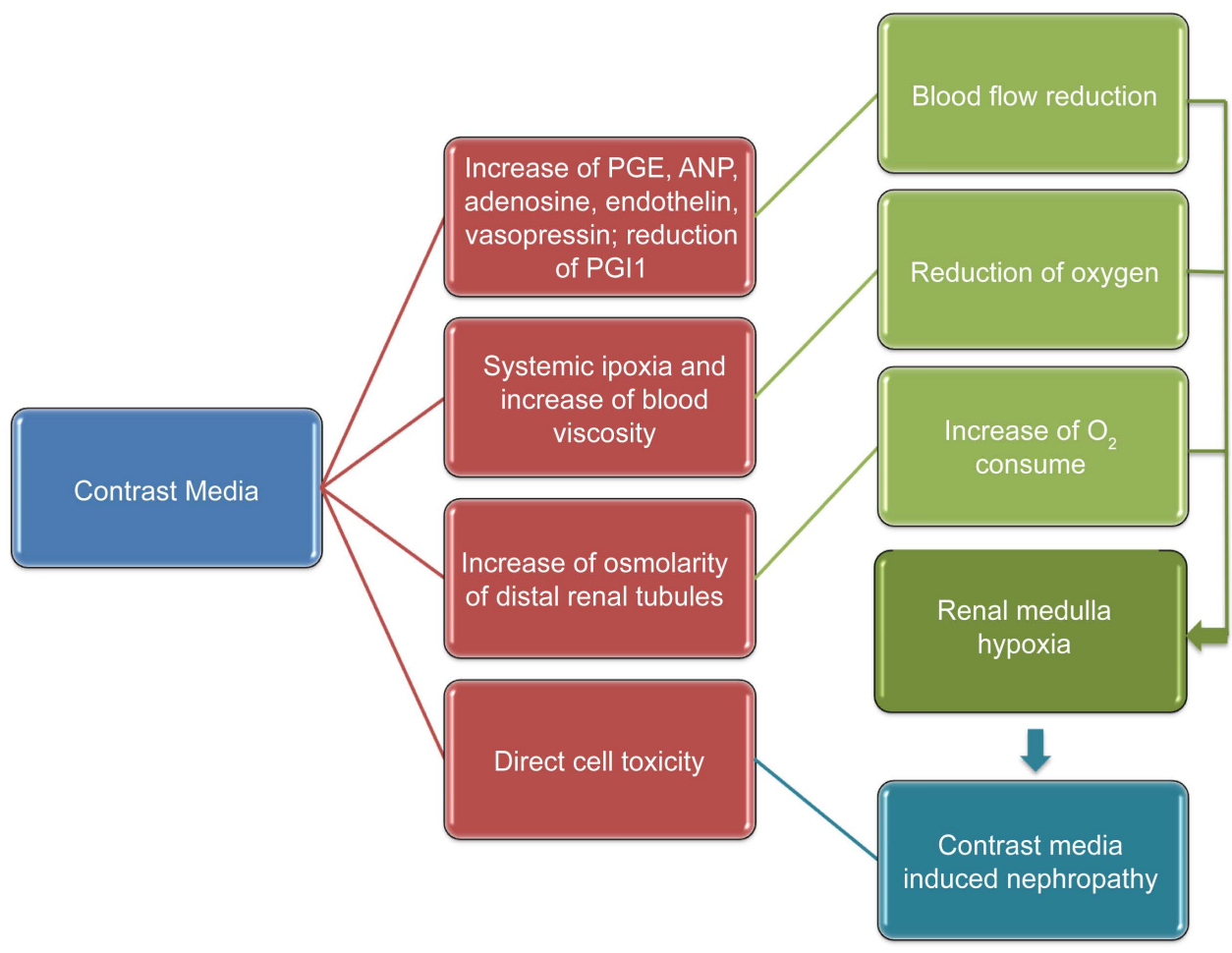

Figure 1. CIN pathogenesis. 


\section{Risk Factors}

The development of CM nephrotoxicity has a significant impact on the duration and costs of hospitalization and on the short and long-term mortality [3]. Therefore, it is necessary to identify conditions that are thought to increase the risk of developing AKI in patients who need to be exposed to diagnostic exams and/or percutaneous procedure with $\mathrm{CM}$ administration.

Among predisposing conditions related to the patient, it is widely recognised the pre-existing kidney injury. There have been also associated (Table 1) advanced age and diabetes mellitus. In addition, numerous studies demonstrated that heart failure is a risk factor for patients undergoing percutaneous coronary intervention [13].

There are factors connected to the procedure such as type, quantity, administration modality (intra-arterial or intra-venous) of CM and interval between multiple administrations. The concurrence of these factors, associated with the population ageing, has been responsible for an increased CIN incidence, which could be avoided by adopting effective preventive measures. Before CM administration, patients should be adequately evaluated, in order to undertake the best preventive strategies to reduce CIN incidence [10].

Thus, it is important to identify the patients who might be particularly exposed [14] [15]. Fortunately, most of the patients who develop CIN have got identifiable risk factors and the results of many studies suggest that CIN onset is directly related to the number of pre-existing risk factors [16]-[18].

\section{Strategies of CIN Risk Prevention}

Here, we discuss about CIN prevention strategies, from the identification of patients at

Table 1. CIN risk factors.

\begin{tabular}{cc}
\hline & Known risk factors \\
Modifiable & Not modifiable \\
High dose of CM & Age $>65$ years \\
Use of iodinated CM & Diabetes mellitus \\
High osmolarity CM & Pre-existing renal impairment \\
Short time interval between two injections of CM & Heart failure (NYHA III-IV) \\
Hypovolaemia & E.F. < 50\% \\
Use of nephrotoxic drugs & Presumptive risk factors \\
\hline Modifiable & Not modifiable \\
\hline Arterial hypertension & Previous kidney surgical interventions \\
Hypercholesterolemia & Vasculitis \\
Hyperlipidemia & Race \\
\hline Hypoalbuminemia &
\end{tabular}


risk and drugs potentially nephrotoxic, to the hydration with possible administration of drugs that appeared to be, in some contexts, nephroprotective, and finally we analyse the radiological procedure aimed at the correct choice of type and administration modality of the CM.

\subsection{Identification of Patients at Risk}

Strategies to reduce CIN incidence first suggest identifying patients at risk and finding for them, when possible, alternative examination tools. They can be identified through the use of questionnaires, the collection of complete anamnesis and the evaluation of glycaemia and, most of all, the assessment of renal function before the CM administration [10].

The glomerular filtration rate (GFR) through either MDRD or Cockroft-Gault formulas correlates with the renal function better than the serous creatinine [19]-[21].

The GFR estimate should be obtained within 3 months before a radiological exam with CM in stable day hospital patients, and within 7 days in the hospitalized ones. The measurement should be the latest possible in patients likely to be affected by a recent modification of the renal function (haemodynamically unstable patients, recent chemotherapy, recent use of nephrotoxic drugs, etc.) [21].

When it is not possible to obtain GFR in due time, for example in Emergency room, the presence of multiple risk factors might indicate patients susceptible of glomerular filtration reduction and therefore renal damage induced by CM [21].

Patients with a GFR $\geq 60 \mathrm{ml} / \mathrm{min}$ have an extremely low CIN risk and, generally, do not require preventive measures or follow-up. Using preventive measures when the GFR is $<60 \mathrm{ml} / \mathrm{min}$ is considered worthwhile. In particular, several studies suggest that GFR cut-off for CIN risk is $40-45 \mathrm{ml} / \mathrm{min}$ and efforts to reduce the CIN risk should be concentrated on patients with GFR $<45 \mathrm{ml} / \mathrm{min}$, with a specific attention to patients with a serious renal dysfunction (GFR $<30 \mathrm{ml} / \mathrm{min}$ ) and additional risk factors [22] [23].

\subsection{Potentially Nephrotoxic Drugs When Associated with CM}

Drugs that may exacerbate CIN can be divided into three categories:

1) FANS, aminoglycosides, cyclosporine, tacrolimus and amphotericin, which act with a direct nephrotoxic mechanism and which is better to suspend at least 24 hours before CM administration [24].

2) Some antihypertensive drugs, among which ACE-inhibitors, angiotensin II receptor antagonists and aliskiren interfere with the renin-angiotensin system and decrease the renal perfusion, particularly when it is based on the renin-angiotensin system (in case of hypovolemia, dehydration, heart failure or renal artery stenosis). It has been recently demonstrated that these drugs represent a risk factor for CIN in patients undergoing coronarography [25]. Nevertheless, there is no evidence that the suspension of these drugs is useful for preventing CIN; hence, to date, it is not recommended their routine interruption [21]. 
3) Metformin, which itself do not increase the CIN risk, may generate lactic acidosis in case of worsening of renal function and it is cause of acute cell damage. For this reason, it is recommended metformin interruption 48 hours before the CM administration in case of pre-existing renal failure (GFR $<60 \mathrm{ml} / \mathrm{min}$ ) and restart 48 hours later, after evaluation of renal function [26]. The European Society of Urogenital Radiology (ESUR) adopts a conservative approach and recommends to continue the therapy with metformin until the CM injection in patients with normal serous creatinine levels and to suspend it 48 hours before the injection in patients with a compromised renal function [21].

\subsection{Detraction or Dose Reduction of Iodinated CM}

Obviously, the risk of CIN onset might be completely avoided obtaining necessary diagnostic data without intravascular administration of iodinated CM [26]. However, in some cases the use of CM is essential but it could be used an inferior dose as the renal toxicity of the iodinated CM is dose-dependent [27].

The CIN prevalence is connected with the CM volume administered, and it has been observed that the lowest rates of CIN risk affect patients receiving less than 100-140 ml of CM. CM administered in volumes higher than $5 \mathrm{ml} / \mathrm{Kg}$ is strongly predictive of a serious acute renal insufficiency, which needs a dialysis treatment [28]. Recent studies found that by using only $50 \%$ of normal dose of CM it is possible to acquire appropriate diagnostic images of peripheral arteries, but reducing CIN development in patients at risk [29].

Moreover, Leheti et al. showed how complications after endovascular aneurism repair appear to be acceptably imaged using only half dose of CM in patients with weight $<90 \mathrm{Kg}$ or $\mathrm{BMI}<35 \mathrm{Kg} / \mathrm{m}^{2}$ [30]. It has been also demonstrated a significant increase of the CIN risk among patients who received a second CM dose within 48 hours after the administration of the first [31]-[33].

It should be reduced the CM volume to the bare minimum, avoiding repeated injections by 72 hours. Moreover, it should be used the minimum amount of iodinated CM which allows satisfying image quality, as it could be often diluted with physiological solution without compromising the image quality [33].

\subsection{Choice of Low-Osmolar Contrast Medium}

One of the advantages of the use of low-osmolar instead of high-osmolar CM is the reduction of CIN incidence in patients at risk [34]. The mechanisms that determine the CIN risk reduction with low-osmolar CM have not been clarified yet. Possible explanations concern the reduced osmolarity itself, the different ionization, and/or other chemical-physical properties [35]. High-osmolar CM are related to more systemic adverse events, including CIN, than low- or iso-osmolar CM. Therefore, the use of CM with higher osmolarity should be avoided in patients with chronic renal insufficiency. In particular, iso-osmolar CM has been demonstrated to be related to low nephrotoxicity, therefore, it has been widely recommended for patients with renal failure [36]. 


\subsection{Hydration}

Hydration is the only accepted prophylactic strategy for CIN and it is strongly recommended by the Guidelines, as it is effective in reducing the risk and severity of the nephropathy [37]-[39]. All the patients considered at CIN risk should receive hydration. The crystalloids generally used are saline isotonic solution and bicarbonate (154 sodium bicarbonate mmol per 0.85 liter of dextrose at 5\%), which are low-cost and harmless for the patients. The possible physiopathological explanation about the hydration efficacy in reducing the CIN risk could be related to the fact that, if correctly completed, it increases the intravascular volume and induces diuresis. Consequently, there is CM dilution in the renal tubules resulting in reduction of its contact time with the tubular epithelium inside the kidney. Moreover, diuresis increase leads to vasodilatation at the level of renal medulla, which is a region more vulnerable to the CM action, probably increasing the prostacyclin production. Furthermore, the volume expansion suppresses the renin-angiotensin system and the anti-diuretic hormone (ADH) production with a vasoconstrictor effect [21]. Particularly for patients with left ventricular dysfunction is important to improve renal blood flow to prevent CIN, as recently demonstrated by Kawatani et al. in a group of patients undergoing endovascular stent graft positioning [40]. Both intravenous and oral hydration have been proposed, however, to the best of our knowledge, there are not strong evidences to consider the oral administration as effective as the intravenous infusion in patients at CIN risk [35] [41]. The most widespread intravenous hydration regime are: $2 \mathrm{ml} / \mathrm{Kg} / \mathrm{h} 2$ hours before CM administration and $1 \mathrm{ml} / \mathrm{Kg}$ in the following 6 hours; or $1 \mathrm{ml} / \mathrm{Kg} / \mathrm{h} 12$ hours before and 12 hours after the procedure [42].

\subsection{Premedication}

Pharmacological prophylaxis for preventing CIN would represent the best result to achieve, however, no medication offers a certain efficacy. In particular, several studies showed the possible role of N-Acetylcysteine (NAC) to prevent CIN due to its double role as vasodilator and antioxidant or because its effect on urine alkalinisation [43][46]. Numerous protocols have been proposed for NAC use. Actually, CIN incidence has been significantly reduced with oral administration of $600 \mathrm{mg}$ of NAC 24 hours before CM injection instead of hydration alone [47]. Another study proposed intravenous NAC 7 hours instead of 20 min before CM injection to prevent CIN after coronarography [45]. In a randomized study, Li et al. compared pre-medication with probu$\mathrm{col}$ and hydration. They demonstrated that oral intake of $500 \mathrm{mg}$ of probucol twice a day for 3 days before and after coronary intervention procedure was associated with lower serum creatinine levels than the hydration group [48]. Another study showed that administration of $3 \mathrm{~g}$ of ascorbic acid before and $2 \mathrm{~g}$ after the procedure markedly reduced the CIN incidence [49]. However, high doses of NAC seem to be more effective than ascorbic acid [50]. Lee et al. attested that a short pre-treatment of $2 \mathrm{mmol} / \mathrm{L}$ of NAC for 15 min before CM injection and a supplementary dose of NAC 12 hours after reduced CIN more than pre-treatment with probucol or ascorbic acid [51]. Neverthe- 
less, data about the efficacy of NAC and other drugs in reducing the incidence of CIN are divergent, therefore, usefulness remain unproven and their use cannot be recommended [52] [53].

\subsection{Haemodialysis and Hemofiltration}

The sense of haemodialysis in patients at high risk for CIN is the early removal of the CM from the blood [54]. Several studies have been published in order to determine if haemodialysis post-administration of CM reduces CIN rate [55]-[57]. A systematic literature review has highlighted that haemodialysis, even if performed after CM administration, is not effective in reducing CIN rate, probably due to the very early CIN development after CM administration [55]. Moreover, haemodialysis simultaneous with $\mathrm{CM}$ administration has not been effective in reducing the damage. In addition, haemodialysis is related to risks connected to the procedure itself, and it can be in some cases nephrotoxic because of phlogosis activation and volume depletion [56].

The hemofiltration is a continuous form of renal replacement therapy. When solutes and water are removed from blood, fluids are substituted by big volumes of isotonic fluid, which help maintaining the hemodynamic stability [58]. With this procedure, most of the CM is removed from blood with the hemofiltration while the isotonic fluid dilutes the remaining CM [59].

The hemofiltration is an expensive procedure, which is performed in intensive care. Even though it may be effective for highly selected patients at extremely high risk of CIN, evidence of its efficacy remains poor [60].

\section{Conclusions}

To date, CIN is one of the most serious adverse reactions to iodinated CM. Since there is no specific therapy for CIN and the disease is iatrogenic, prevention is of paramount importance [45]. The patients at highest risk have a GFR below $60 \mathrm{ml} / \mathrm{min}$. GFR measurement is particularly recommended before intravascular administration of iodinated $\mathrm{CM}$ in patients affected by renal disease, positive familiar anamnesis, renal insufficiency, diabetes under medical therapy, vascular collagen diseases, previous renal surgery or which are under treatment with metformin or nephrotoxic drugs like aminoglycosides and nonsteroidal anti-inflammatory [61] [62]. All patients should be persuaded to freely drink water 12 hours before and after CM injection, when possible. Intravenous hydration, which expands the blood volume, is the only intervention to limit hypoxic damage and direct toxic effect of CM and to prevent CIN. The hydration protocols consider $1-1.5 \mathrm{ml} / \mathrm{kg} / \mathrm{h}$ intravenous saline isotonic solution administration 6 12 hours before the CM administration and for 6 - 24 hours after. For hospitalized patients, it should be applied a 24-hour protocol which includes $1 \mathrm{ml} / \mathrm{Kg} / \mathrm{h}$ of saline solution administration, beginning 12 hours before and continuing for 12 hours after $\mathrm{CM}$ injection [63].

No pharmacological prophylaxis (with vasodilators that have a renal action, receptor antagonists of endogenous vasoactive mediators, cytoprotective drugs) has been 


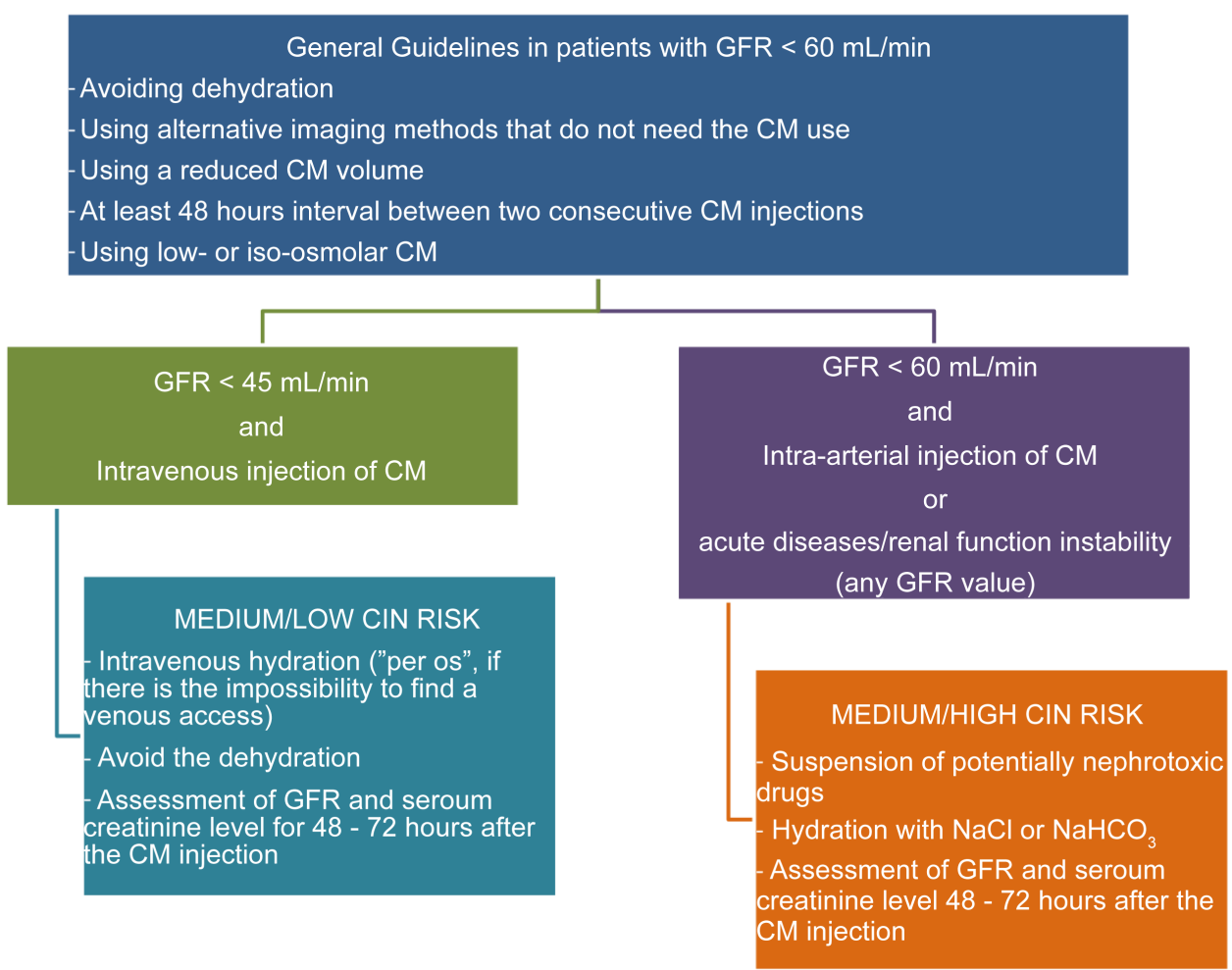

Figure 2. Guidelines for patients with GFR $<60 \mathrm{ml} / \mathrm{min}$ modified from Owen RJ et al. [64].

demonstrated to be useful in preventing the nephropathy caused by CM. The hydration pre- and post-CM administration represents the only prevention therapy strongly recommended by the guidelines for patients at risk (Figure 2) [10] [21] [64].

\section{Acknowledgements}

The authors would like to thank Dr.ssa Valentina Felicita Lapelosa for her contribution to the preparation of the manuscript.

\section{Conflict of Interest}

The authors declare that they have no conflict of interest.

\section{References}

[1] McCullough, P.A. (2008) Contrast-Induced Acute Kidney Injury. Journal of the American College of Cardiology, 51, 1419-1428. http://dx.doi.org/10.1016/j.jacc.2007.12.035

[2] Matsuo, S., Imai, E., Horio, M., et al. (2009) Revised Equations for Estimated GFR from Serum Creatinine in Japan. American Journal of Kidney Diseases, 53, 982-992. http://dx.doi.org/10.1053/j.ajkd.2008.12.034

[3] Subramanian, S., Tumlin, J., Bapat, B. and Zyczynski, T. (2007) Economic Burden of Contrast-Induced Nephropathy: Implications for Prevention Strategies. Journal of Medical Economics, 10, 119-134. http://dx.doi.org/10.3111/200710119134

[4] Rihal, C.S., Textor, S.C., Grill, D.E., et al. (2002) Incidence and Prognostic Importance of Acute Renal Failure after Percutaneous Coronary Intervention. Circulation, 105, 2259- 
2264. http://dx.doi.org/10.1161/01.CIR.0000016043.87291.33

[5] Hou, S.H., Bushinsky, D.A., Wish, J.B., Cohen, J.J. and Harrington, J.T. (1983) HospitalAcquired Renal Insufficiency: A Prospective Study. American Journal of Medicine, 74, 243248. http://dx.doi.org/10.1016/0002-9343(83)90618-6

[6] McCullough, P.A., Wolyn, R., Rocher, L.L., Levin, R.N. and O’Neill, W.W. (1997) Acute Renal Failure after Coronary Intervention: Incidence, Risk Factors, and Relationship to Mortality. American Journal of Medicine, 103, 368-375.

http://dx.doi.org/10.1016/S0002-9343(97)00150-2

[7] Nash, K., Hafeez, A. and Hou, S. (2002) Hospital-Acquired Renal Insufficiency. American Journal of Kidney Diseases, 39, 930-936. http://dx.doi.org/10.1053/ajkd.2002.32766

[8] Levy, E.M., Viscoli, C.M. and Horwitz, R.I. (1996) The Effect of Acute Renal Failure on Mortality. A Cohort Analysis. JAMA, 275, 1489-1494.

http://dx.doi.org/10.1001/jama.1996.03530430033035

[9] Barrett, B.J. and Carlisle, E.J. (1993) Metaanalysis of the Relative Nephrotoxicity of Highand Low-Osmolality Iodinated Contrast Media. Radiology, 188, 171-178. http://dx.doi.org/10.1148/radiology.188.1.8511292

[10] Morcos, S.K., Thomsen, H.S. and Webb, J.A. (1999) Contrast-Media-Induced Nephrotoxicity: A Consensus Report. Contrast Media Safety Committee, European Society of Urogenital Radiology (ESUR). European Radiology, 9, 1602-1613. http://dx.doi.org/10.1007/s003300050894

[11] Mueller, C. (2006) Prevention of Contrast-Induced Nephropathy with Volume Supplementation. Kidney International Supplements, 69, S16-S19. http://dx.doi.org/10.1038/sj.ki.5000369

[12] Bakris, G.L., Lass, N., Gaber, A.O., Jones, J.D. and Burnett Jr., J.C. (1990) Radiocontrast Medium-Induced Declines in Renal Function: A Role for Oxygen Free Radicals. American Journal of Physiology, 258, F115-F120.

[13] Li, H., Huang, S. and He, Y. (2016) Impact of an Early Decrease in Systolic Blood Pressure on the Risk of Contrast-Induced Nephropathy after Percutaneous Coronary Intervention. Heart, Lung and Circulation, 25, 118-123. http://dx.doi.org/10.1016/j.hlc.2015.07.013

[14] Cochran, S.T. (1997) Determination of Serum Creatinine Level Prior to Administration of Radiographic Contrast Media. JAMA, 277, 517-518. http://dx.doi.org/10.1001/jama.1997.03540310015008

[15] Tippins, R.B., Torres, W.E., Baumgartner, B.R. and Baumgarten, D.A. (2000) Are Screening Serum Creatinine Levels Necessary Prior to Outpatient CT Examinations? Radiology, 216, 481-484. http://dx.doi.org/10.1148/radiology.216.2.r00au23481

[16] Bartholomew, B.A., Harjai, K.J., Dukkipati, S., et al. (2004) Impact of Nephropathy after Percutaneous Coronary Intervention and a Method for Risk Stratification. American Journal of Cardiology, 93, 1515-1519. http://dx.doi.org/10.1016/j.amjcard.2004.03.008

[17] Mehran, R., Aymong, E.D., Nikolsky, E., et al. (2004) A Simple Risk Score for Prediction of Contrast-Induced Nephropathy after Percutaneous Coronary Intervention: Development and Initial Validation. Journal of the American College of Cardiology, 44, 1393-1399. http://dx.doi.org/10.1016/j.jacc.2004.06.068

[18] Rich, M.W. and Crecelius, C.A. (1990) Incidence, Risk Factors, and Clinical Course of Acute Renal Insufficiency after Cardiac Catheterization in Patients 70 Years of Age or Older. A Prospective Study. Archives of Internal Medicine, 150, 1237-1242. http://dx.doi.org/10.1001/archinte.1990.00390180067011

[19] Cockcroft, D.W. and Gault, M.H. (1976) Prediction of Creatinine Clearance from Serum 
Creatinine. Nephron, 16, 31-41. http://dx.doi.org/10.1159/000180580

[20] Harmoinen, A., Lehtimaki, T., Korpela, M., Turjanmaa, V. and Saha, H. (2003) Diagnostic Accuracies of Plasma Creatinine, Cystatin C, and Glomerular Filtration Rate Calculated by the Cockcroft-Gault and Levey (MDRD) Formulas. Clinical Chemistry, 49, 1223-1225. http://dx.doi.org/10.1373/49.7.1223

[21] Stacul, F., van der Molen, A.J. and Reimer, P., et al. (2011) Contrast Media Safety Committee of European Society of Urogenital Radiology (ESUR). Contrast Induced Nephropathy: Updated ESUR Contrast Media Safety Committee Guidelines. European Radiology, 21, 2527-2541. http://dx.doi.org/10.1007/s00330-011-2225-0

[22] Katzberg, R.W. and Newhouse, J.H. (2010) Intravenous Contrast Medium-Induced Nephrotoxicity: Is the Medical Risk Really as Great as We Have Come to Believe? Radiology, 256, 21-28. http://dx.doi.org/10.1148/radiol.10092000

[23] Manske, C.L., Sprafka, J.M., Strony, J.T. and Wang, Y. (1990) Contrast Nephropathy in Azotemic Diabetic Patients Undergoing Coronary Angiography. American Journal of Medicine, 89, 615-620. http://dx.doi.org/10.1016/0002-9343(90)90180-L

[24] Lameire, N.H. (2006) Contrast-Induced Nephropathy-Prevention and Risk Reduction. Nephrology Dialysis Transplantation, 21, i11-i23. http://dx.doi.org/10.1093/ndt/gfl215

[25] Goo, J.J., Kim, J.J., Kang, J.H., et al. (2014) Effect of Renin-Angiotensin-System Blockers on Contrast-Medium-Induced Acute Kidney Injury after Coronary Angiography. Korean Journal of Internal Medicine, 29, 203-209. http://dx.doi.org/10.3904/kjim.2014.29.2.203

[26] Pfister, S.A., Deckart, A., Laschke, S., et al. (2003) Unenhanced Helical Computed Tomography vs Intravenous Urography in Patients with Acute Flank Pain: Accuracy and Economic Impact in a Randomized Prospective Trial. European Radiology, 13, 2513-2520. http://dx.doi.org/10.1007/s00330-003-1937-1

[27] American College of Rheumatology (2016) Post-Contrast Acute Kidney Injury and Contrast-Induced Nephropathy in Adults. In: ACR Manual on Contrast Media, Version 10.2, American College of Rheumatology, 33-44.

[28] Freeman, R.V., O’Donnell, M., Share, D., et al. (2002) Nephropathy Requiring Dialysis after Percutaneous Coronary Intervention and the Critical Role of an Adjusted Contrast Dose. American Journal of Cardiology, 90, 1068-1073. http://dx.doi.org/10.1016/S0002-9149(02)02771-6

[29] Almutairi, A., Sun, Z., Poovathumkadavi, A. and Assar, T. (2015) Dual Energy CT Angiography of Peripheral Arterial Disease: Feasibility of Using Lower Contrast Medium Volume. Zhang, H., Ed., PLoS ONE, 10, e0139275.

[30] Lehti, L., Nyman, U., Söderberg, M., Björses, K., Gottsäter, A. and Wassélius, J. (2016) 80-kVp CT Angiography for Endovascular Aneurysm Repair Follow-Up with Halved Contrast Medium Dose and Preserved Diagnostic Quality. Acta Radiologica, 57, 279-286. http://dx.doi.org/10.1177/0284185115577251

[31] Abujudeh, H.H., Gee, M.S. and Kaewlai, R. (2009) In Emergency Situations, Should Serum Creatinine Be Checked in All Patients before Performing Second Contrast CT Examinations within 24 Hours? Journal of the American College of Radiology, 6, 268-273. http://dx.doi.org/10.1016/j.jacr.2008.09.014

[32] Thomsen, H.S., Morcos, S.K. and Barrett, B.J. (2008) Contrast-Induced Nephropathy: The Wheel Has Turned 360 Degrees. Acta Radiologica, 49, 646-657. http://dx.doi.org/10.1080/02841850801995413

[33] Trivedi, H. and Foley, W.D. (2010) Contrast-Induced Nephropathy after a Second Contrast Exposure. Renal Failure, 32, 796-801. http://dx.doi.org/10.3109/0886022X.2010.495441 
[34] Ellis, J.H., Cohan, R.H., Sonnad, S.S. and Cohan, N.S. (1996) Selective Use of Radiographic Low-Osmolality Contrast Media in the 1990s. Radiology, 200, 297-311.

http://dx.doi.org/10.1148/radiology.200.2.8685315

[35] McCullough, P.A., Bertrand, M.E., Brinker, J.A. and Stacul, F. (2006) A Meta-Analysis of the Renal Safety of Isosmolar Iodixanol Compared with Low-Osmolar Contrast Media. Journal of the American College of Cardiology, 48, 692-699. http://dx.doi.org/10.1016/j.jacc.2006.02.073

[36] Aspelin, P., Aubry, P., Fransson, S.G., Strasser, R., Willenbrock, R. and Berg, K.J. (2003) Nephrotoxic Effects in High-Risk Patients Undergoing Angiography. Nephrotoxicity in High-Risk Patients Study of Iso-Osmolar and Low-Osmolar Non-Ionic Contrast Media Study Investigators. New England Journal of Medicine, 348, 491-499. http://dx.doi.org/10.1056/NEJMoa021833

[37] Thomsen, H.S. (2007) Current Evidence on Prevention and Management of ContrastInduced Nephropathy. European Radiology, 17, F33-F37. http://dx.doi.org/10.1007/s10406-007-0226-5

[38] Mueller, C., Buerkle, G., Buettner, H.J., et al. (2002) Prevention of Contrast Media-Associated Nephropathy: Randomized Comparison of 2 Hydration Regimens in 1620 Patients Undergoing Coronary Angioplasty. Archives of Internal Medicine, 162, 329-336. http://dx.doi.org/10.1001/archinte.162.3.329

[39] Weisbord, S.D. and Palevsky, P.M. (2008) Prevention of Contrast-Induced Nephropathy with Volume Expansion. Clinical Journal of the American Society of Nephrology, 3, 273 280. http://dx.doi.org/10.2215/CJN.02580607

[40] Kawatani, Y., Nakamura, Y. and Mochida, Y. (2016) Contrast Medium Induced Nephropathy after Endovascular Stent Graft Placement: An Examination of Its Prevalence and Risk Factors. Radiology Research and Practice, 2016, Article ID: 5950986.

http://dx.doi.org/10.1155/2016/5950986

[41] Stacul, F., Adam, A., Becker, C.R., et al. (2006) CIN Consensus Working Panel. Strategies to Reduce the Risk of Contrast-Induced Nephropathy. American Journal of Cardiology, 98, 59K-77K. http://dx.doi.org/10.1016/j.amjcard.2006.01.024

[42] Solomon, R., Werner, C., Mann, D., D’Elia, J. and Silva, P. (1994) Effects of Saline, Mannitol, and Furosemide to Prevent Acute Decreases in Renal Function Induced by Radiocontrast Agents. New England Journal of Medicine, 331, 1416-1420. http://dx.doi.org/10.1056/NEJM199411243312104

[43] Baker, C.S., Wragg, A., Kumar, S., De Palma, R., Baker, L.R. and Knight, C.J. (2003) A Rapid Protocol for the Prevention of Contrast-Induced Renal Dysfunction: The RAPPID Study. Journal of the American College of Cardiology, 41, 2114-2118. http://dx.doi.org/10.1016/S0735-1097(03)00487-X

[44] Marenzi, G., Assanelli, E., Marana, I., et al. (2006) $N$-Acetylcysteine and Contrast-Induced Nephropathy in Primary Angioplasty. New England Journal of Medicine, 354, 2773-2782. http://dx.doi.org/10.1056/NEJMoa054209

[45] Abouzeid, S. and Mosbah, O. (2016) Evaluation of Different Sodium Bicarbonate Regimens for the Prevention of Contrast Medium-Induced Nephropathy. Electronic Physician, 8, 1973-1977. http://dx.doi.org/10.19082/1973

[46] Kelly, A.M., Dwamena, B., Cronin, P., Bernstein, S.J. and Carlos, R.C. (2008) Meta-Analysis: Effectiveness of Drugs for Preventing Contrast-Induced Nephropathy. Annals of Internal Medicine, 148, 284-294.

http://dx.doi.org/10.7326/0003-4819-148-4-200802190-00007 
[47] Fishbane, S., Durham, J.H., Marzo, K. and Rudnick, M. (2004) $N$-Acetylcysteine in the Prevention of Radiocontrast-Induced Nephropathy. Journal of the American Society of Nephrology, 15, 251-260. http://dx.doi.org/10.1097/01.ASN.0000107562.68920.92

[48] Li, G., Yin, L., Liu, T., et al. (2009) Role of Probucol in Preventing Contrast-Induced Acute Kidney Injury after Coronary Interventional Procedure. American Journal of Cardiology, 103, 512-514. http://dx.doi.org/10.1016/j.amjcard.2008.10.009

[49] Alexopoulos, E., Spargias, K., Kyrzopoulos, S., et al. (2010) Contrastinduced Acute Kidney Injury in Patients with Renal Dysfunction Undergoing a Coronary Procedure and Receiving Non-Ionic Low-Osmolar versus Iso-Osmolar Contrast Media. American Journal of the Medical Sciences, 339, 25-30. http://dx.doi.org/10.1097/MAJ.0b013e3181c06e70

[50] Jo, S.H., Koo, B.K., Park, J.S., et al. (2009) N-Acetylcysteine versus Ascorbic Acid for Preventing Contrast-Induced Nephropathy in Patients with Renal Insufficiency Undergoing Coronary Angiography: NASPI Study-A Prospective Randomized Controller Trial. American Heart Journal, 157, 576-583. http://dx.doi.org/10.1016/j.ahj.2008.11.010

[51] Lee, H.C., Sheu, S.H., Liu, I.H., et al. (2012) Impact of Short-Duration Administration of $N$-Acetylcysteine, Probucol and Ascorbic Acid on Contrast-Induced Cytotoxicity. Journal of nephrology, 25, 56-62.

[52] Hoffmann, U., Fischereder, M., Krüger, B., Drobnik, W. and Krämer, B.K. (2004) The Value of $N$-Acetylcysteine in the Prevention of Radiocontrast Agent-Induced Nephropathy Seems Questionable. Journal of the American Society of Nephrology, 15, 407-410. http://dx.doi.org/10.1097/01.ASN.0000106780.14856.55

[53] Gonzales, D.A., Norsworthy, K.J., Kern, S.J., et al. (2007) A Meta-Analysis of $N$-Acetylcysteine in Contrast-Induced Nephrotoxicity: Unsupervised Clustering to Resolve Heterogeneity. BMC Medicine, 5, 32. http://dx.doi.org/10.1186/1741-7015-5-32

[54] Guastoni, C., De Servi, S. and D’Amico, M. (2007) The Role of Dialysis in Contrast-Induced Nephropathy: Doubts and Certainties. Journal of Cardiovascular Medicine, 8, 549-557. http://dx.doi.org/10.2459/01.JCM.0000281709.43681.a5

[55] Cruz, D.N., Perazella, M.A., Bellomo, R., et al. (2006) Extracorporeal Blood Purification Therapies for Prevention of Radiocontrast-Induced Nephropathy: A Systematic Review. American Journal of Kidney Diseases, 48, 361-371. http://dx.doi.org/10.1053/j.ajkd.2006.05.023

[56] Vogt, B., Ferrari, P., Schönholzer, C., et al. (2001) Prophylactic Hemodialysis after Radiocontrast Media in Patients with Renal Insufficiency Is Potentially Harmful. American Journal of Medicine, 111, 692-698. http://dx.doi.org/10.1016/S0002-9343(01)00983-4

[57] Lehnert, T., Keller, E., Gondolf, K., Schäffner, T., Pavenstädt, H. and Schollmeyer, P. (1998) Effect of Haemodialysis after Contrast Medium Administration in Patients with Renal Insufficiency. Nephrology Dialysis Transplantation, 13, 358-362. http://dx.doi.org/10.1093/oxfordjournals.ndt.a027830

[58] Marenzi, G., Lauri, G., Campodonico, J., et al. (2006) Comparison of Two Hemofiltration Protocols for Prevention of Contrast-Induced Nephropathy in High-Risk Patients. American Journal of Medicine, 119, 155-162. http://dx.doi.org/10.1016/j.amjmed.2005.08.002

[59] Marenzi, G., Marana, I., Lauri, G., et al. (2003) The Prevention of Radiocontrast-AgentInduced Nephropathy by Hemofiltration. New England Journal of Medicine, 349, 1333 1340. http://dx.doi.org/10.1056/NEJMoa023204

[60] Sterling, K.A., Tehrani, T. and Rudnick, M.R. (2008) Clinical Significance and Preventive Strategies for Contrast-Induced Nephropathy. Current Opinion in Nephrology and Hypertension, 17, 616-623. http://dx.doi.org/10.1097/MNH.0b013e32830f45a3 
[61] Thomsen, H.S. and Morcos, S.K. (1999) Contrast Media and Metformin: Guidelines to Diminish the Risk of Lactic Acidosis in Non-Insulin-Dependent Diabetics after Administration of Contrast Media. ESUR Contrast Media Safety Committee. European Radiology, 9, 738-740. http://dx.doi.org/10.1007/s003300050746

[62] Herts, B.R., Schneider, E., Poggio, E.D., Obuchowski, N.A. and Baker, M.E. (2008) Identifying Outpatients with Renal Insufficiency before Contrast-Enhanced CT by Using Estimated Glomerular Filtration Rates versus Serum Creatinine Levels. Radiology, 248, 106113. http://dx.doi.org/10.1148/radiol.2481071528

[63] Mueller, C. (2006) Prevention of Contrast-Induced Nephropathy with Volume Supplementation. Kidney International Supplements, 69, S16-S19. http://dx.doi.org/10.1038/sj.ki.5000369

[64] Owen, R.J., Hiremath, S., Myers, A., Fraser-Hill, M. and Barrett, B.J. (2014) Canadian Association of Radiologists Consensus Guidelines for the Prevention of Contrast-Induced Nephropathy: Update 2012. Canadian Association of Radiologists Journal, 65, 96-105. http://dx.doi.org/10.1016/j.carj.2012.11.002

\section{Abbreviation Note List}

CIN: Contrast medium Induced Nephropathy

AKI: Acute Kidney Injury

CM: Contrast Medium

GFR: Glomerular Filtration Rate

ADH: Anti-Diuretic Hormone

NAC: N-AcetylCysteine

\section{Submit or recommend next manuscript to SCIRP and we will provide best service for you:}

Accepting pre-submission inquiries through Email, Facebook, LinkedIn, Twitter, etc. A wide selection of journals (inclusive of 9 subjects, more than 200 journals)

Providing 24-hour high-quality service

User-friendly online submission system

Fair and swift peer-review system

Efficient typesetting and proofreading procedure

Display of the result of downloads and visits, as well as the number of cited articles

Maximum dissemination of your research work

Submit your manuscript at: http://papersubmission.scirp.org/

Or contact ojneph@scirp.org 